\title{
Glatiramer acetate: a complex drug beyond biologics
}

Paolo Rocco ${ }^{1}$, Ivano Eberini ${ }^{2}$, Umberto M. Musazzi ${ }^{1}$, Silvia Franzè ${ }^{1}$, Paola Minghetti ${ }^{1}$

${ }^{1}$ Dipartimento di Scienze Farmaceutiche, Università degli Studi di Milano, via G. Colombo, 71 20133 Milan, Italy.

${ }^{2}$ Dipartimento di Scienze Farmacologiche e Biomolecolari, Università degli Studi di Milano, via G.

Balzaretti, 9 - 20133 Milan, Italy

Corresponding Author: Minghetti, P. (paola.minghetti@unimi.it). Phone: +39(2)20324639.

Keywords: NBCD; complex drug; glatiramer; glatiramoid.

\section{Conflict of Interest Statement}

IE acted as an expert consultant for Teva Italia.

All other authors declare they have no conflict of interest. 


\section{Introduction}

Complex drugs may be either biological, if the active ingredients are derived from a biological source, or non-biological, if obtained by chemical synthesis. In both cases their quality depends considerably on the manufacturing process and they cannot be completely characterized with current analytical methods [1]. In the case of Non Biological Complex Drugs (NBCDs), in particular, "the active substance is not a homomolecular structure, but consists of different (closely related and often nanoparticulate) structures that cannot be isolated and fully quantitated, characterized and/or described by physico-chemical analytical means" [2]. The complex nature of NBCDs may arise either from the active substance (e.g. glatiramer acetate), or from other sources, such as the formulation (e.g. liposomes) [3].

In this paper, the case of medicinal products containing glatiramer acetate (GA) - a NBCD relevant for clinical and economic reasons - is reviewed. We consider both the originator, marketed by Teva under the brand name Copaxone ${ }^{\circledR}$, and its copies, marketed by Mylan and Sandoz in the US as Glatiramer acetate and Glatopa ${ }^{\circledR}$, respectively, and by Synthon in the EU as Copemyl (and other brand names depending on the Member State). The differences between US and EU regulatory policies are also highlighted. Indeed, since bioequivalence is appropriate to assure therapeutic equivalence only when pharmaceutical equivalence can be proved, which is not the case of originator GA and its copies, regulatory agencies in different jurisdictions have addressed the issue in different ways.

GA has been approved, in the US and Europe, as a disease-modifying treatment (DMT) for patients with relapsing forms of Multiple Sclerosis (MS) [4]. MS is a chronic, inflammatory, autoimmune disease of the central nervous system (CNS), characterized by disruption of myelin, ensheathing axons, and axonal damage [5] and by a heterogeneous course and clinical symptoms [6]. MS starts as an autoimmune reaction leading to acute CNS inflammation, which is followed by plaques of demyelination [7] and axonal damage. It usually starts as a relapsing-remitting disease 
but can evolve into a chronic progressive $(\mathrm{CP})$ phase characterized by continuous accumulation of neurological deficits, even if different courses for MS have been described [8]. While treatment of relapsing-remitting (RRMS) has improved dramatically through therapies mostly aimed at reducing the autoimmune inflammation in the CNS, no drugs promoting remyelination, axonal recovery and neuronal preservation for progressive MS are available [5]. Current treatments depend upon patient's classification and response to therapy, but all the available drugs are mainly aimed at controlling inflammation and suppressing/modulating patients' immune response [9].

\section{Scientific Background}

Glatiramer acetate is a heterogeneous mixture of not fully characterized synthetic polypeptides, containing L-alanine, L-lysine, L-glutamic acid, L-tyrosine in the constant molar ratio 0.43:0.34:0.14:0.09. Average molecular weight (MW) of the polypeptides ranges from 5 to $9 \mathrm{kDa}$, with a distribution range from 2.5 to $20 \mathrm{kDa}[10,11,12]$. As an example, a polypeptide constituted by 60 amino acids, with a MW of about $7 \mathrm{kDa}$, will contain (on average) 26 Alanine, 20 Lysine, 8 Glutamic Acid and 6 Tyrosine residues, which account for $10^{29}$ possible sequences [13].

The amino acid sequences are not completely random, being the result of both the physicochemical properties of the starting materials and the fundamental reaction scheme. However, they are not completely conserved from batch to batch, even when the process is tightly controlled. Indeed along with conserved characteristics - such as amino acid molar ratio - other characteristics - such as the specific amino acid sequences - will show batch-to-batch variability [14]. The quality of glatiramoids is therefore heavily dependent on the manufacturing process [15, 16], as was clear in the case of protiramer (TV-5010), obtained by Teva after changes in the manufacturing process of Copaxone ${ }^{\circledR}$. Though having the same molar ratio of amino acids as GA and similar physicochemical parameters, but higher average MW, protiramer showed a different in vivo safety profile which prevented its marketing [17]. 
Neither the exact mechanism of action of GA nor the specific peptides responsible for its therapeutic effect are known [16]. The mechanism of action probably involves modifications of immune processes responsible for the pathogenesis of MS, as suggested by studies exploring the pathogenesis of experimental allergic encephalomyelitis (EAE) in both animal models and MS patients, which showed that GA-specific suppressor T cells are induced [10].

\section{Data required for the Marketing Authorisation of Copaxone ${ }^{\circledR}$}

NBCDs are not classified as a distinct category of medicinal products by US or EU regulatory agencies. Their copies are generally considered as generics in the US [18], but may undergo different regulatory pathways in the EU, where most NBCDs applications are managed by national Agencies $[3,19,20]$.

Copaxone ${ }^{\circledR}$ was first authorized in Israel and then in the United States in 1996, based on two clinical trials (named Study 1 and Study 2 in the subsequent section) [21]. Other two studies employing imaging endpoints (Study 3 and Study 4) have been subsequently submitted by Teva both to US and EU regulatory authorities. As of 2018, the efficacy of Copaxone ${ }^{\circledR}$ is supported by evidence derived from five clinical trials: the first four (Studies 1,2,3,4) used Copaxone® $20 \mathrm{mg} / \mathrm{ml}$ once per day (OD), the last (Study 5) used Copaxone ${ }^{\circledR} 40 \mathrm{mg} / \mathrm{ml}$ thrice in week (TIW) [22]. In the US, Copaxone ${ }^{\circledR}$ "is indicated for the treatment of patients with relapsing forms of multiple sclerosis" [22].

In the European Union, Copaxone ${ }^{\circledR} 20 \mathrm{mg} / \mathrm{ml}$ was initially approved in the UK, in 2000, as Powder and Solvent for Solution for Injection [23]. Subsequently, a UK national license for Copaxone® $20 \mathrm{mg} / \mathrm{ml}$ Solution for Injection, Prefilled Syringe was granted on 7 April 2003. Marketing Authorisations (MAs) by a Mutual Recognition Procedure (Reference Member State: UK) in other EU countries followed: Austria, Belgium, Denmark, Finland, Germany, Greece, Iceland, Ireland, Italy, Luxembourg, The Netherlands, Norway, Portugal, Spain and Sweden, in 2004; Cyprus, Czech Republic, Estonia, Hungary, Latvia, Lithuania, Malta, Poland, Slovak 
Republic and Slovenia in 2006. Applications were made under Article 8.3 of directive 2001/83/EC (hybrid application) [10]. In the EU, Copaxone® is indicated "for the treatment of patients who have experienced a well-defined first clinical episode and are determined to be at high risk of developing clinically definite multiple sclerosis $(C D M S)$ ". Copaxone® is also indicated "for the reduction in frequency of relapses in ambulatory patients, (i.e. who can walk unaided) with relapsing, remitting multiple sclerosis $(M S)$ characterized by at least two attacks of neurological dysfunction over the preceding two-year period" [24].

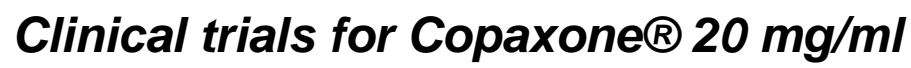

Following is a summary of clinical trials for Copaxone ${ }^{\circledR}[21,25]$.

Study 1 was a two-year study involving 50 patients diagnosed with RRMS with at least two attacks of neurological dysfunction (relapses). Patients were randomized to either Copaxone ${ }^{\circledR} 20 \mathrm{mg}$ OD or placebo in a 1:1 ratio and examined every three months or after a presumed exacerbation. Data shows a significant increase of the number relapse-free patients (primary outcome) in the Copaxone ${ }^{\circledR}$ group compared with that in the placebo group (Table 1). Secondary outcomes were: (1) the frequency of attacks; (2) the median time to first relapse; (3) the proportion of progression-free patients (where progression denoted an increase of at least one point on the Disability Status Scale for at least three consecutive months); (4) the number of relapses during the study compared to the number of relapses in the previous two years.

Study 2 (Protocol 01-9001) was a multicenter trial performed in 11 US centers, with the same inclusion criteria as Study 1. 251 patients were randomized to either Copaxone® $20 \mathrm{mg}$ OD or placebo in a 1:1 ratio. The relapse rate (primary outcome) was $29 \%$ lower in the Copaxone ${ }^{\circledR}$ group with respect to the placebo group. Copaxone ${ }^{\circ}$, however, did not show any beneficial effect on the progression of disability (Table 2).

Study 3 and Study 4 were based on Magnetic Resonance Imaging (MRI) endpoints. In MRI hydrogen nuclei (protons) immersed in a magnetic field resonate with a spectrum of applied radio 
frequencies. Those protons resonate at frequencies characteristic of their environment, in our case tissues and organs. When radio frequencies are stopped, protons cease to resonate and return to their lower energy state with different relaxation times. Quick relaxation times are referred to as $\mathrm{T} 1$ and late ones as T2, and images can be weighted based on one (T1-weighted) or the other (T2-weighted). By pulsing the radio waves with a short interval (called repetition time, or TR) between pulses, T1weighted images can be obtained, which are particularly useful for showing anatomical details. By employing trains of radio pulses to generate echoes at specific echo times (TE), T2-weighted images can be obtained, which are particularly useful for showing pathological changes in tissues. By mixing short TRs and long TEs data so called proton-density images can be produced, which are better for distinguishing cerebrospinal fluid from brain. Gadolinium (Gd) diethylenetriamine penta-acetic acid (DTPA), a paramagnetic intravenous contrast agent, is commonly used to enhance T1-weighted scans. Gadolinium enhanced T1-weighted images are the most widely used at present, as they are obtained much faster than T2-weighted images and correlate better with clinical phenomena [25].

Study 3 was a three-year placebo-controlled trial, followed by an open label treatment (up to five years). It involved 481 patients $\left(\right.$ Copaxone $^{\circledR} n=243$, placebo $n=238$ ) with a clinically isolated syndrome (CIS) and MRI data highly suggestive of MS. Copaxone ${ }^{\circledR}$ was shown to delay significantly the progression from the first CIS to clinically definite multiple sclerosis (CDMS), with a risk reduction of $45 \%$ (Hazard Ratio $=0.55 ; 95 \%$ CI $[0.40 ; 0.77]$, -value $=0.0005)$, during the placebocontrolled period. Moreover, $25 \%$ of the patients in the Copaxone ${ }^{\circledR}$ group progressed to CDMS vs. $43 \%$ in the placebo group. Those effects were confirmed in a long-term follow-up [26].

Study 4 (Protocol 9003) was a nine-month, multinational, double blind study with MRI parameters as primary and secondary outcomes. It involved 239 patients with at least one Gdenhancing lesion randomized to receive either Copaxone ${ }^{\circledR} 20 \mathrm{mg}$ OD $(n=119)$ or placebo $(\mathrm{n}=120)$. Copaxone ${ }^{\circledR}$ showed a reduction in the total cumulative number of $\mathrm{T} 1 \mathrm{Gd}$-enhancing lesions over the study duration (primary endpoint) with respect to placebo from 17 to 11 ( $\mathrm{p}$-value $=0.0030$ ). Data showed a beneficial effect of Copaxone ${ }^{\circledR}$ over placebo [21,25]. 


\section{Clinical trials for Copaxone $\mathbb{R}^{40} \mathrm{mg} / \mathrm{ml}$}

Of the three clinical trials performed on Copaxone® $40 \mathrm{mg} / \mathrm{ml}$, only GALA (Study 5) contributed new data to efficacy analysis. Trials GA/9006 and GE/9016 did not contribute to efficacy analysis of Copaxone ${ }^{\circledR} 40 \mathrm{mg} / \mathrm{ml}$, but only to safety analysis [21].

Study 5 (MS-GA-301 GALA) [27] was double-blind, placebo-controlled, multinational study. Patients ( $\mathrm{n}=1404)$ with RRMS were randomized in a 2:1 ratio to either Copaxone ${ }^{\circledR} 40 \mathrm{mg}$ TIW or placebo for one year (Table 3) [21, 28].

In the GA/9006 [29] and GA/9016 FORTE study [30] patients with RRMS were randomized to either Copaxone ${ }^{\circledR} 20 \mathrm{mg}$ OD or Copaxone ${ }^{\circledR} 40 \mathrm{mg}$ OD in a 1:1 ratio. GA/9006 was a phase 2 double-blind, parallel group 36 week trial on 90 patients. As a primary endpoint, the total number of T1-Gd enhancing lesions measured at months 7 to 9 was used. The GA/9016 FORTE study was a 12 month, double-blind, actively controlled two arm multinational trial on 1155 patients. As a primary endpoint the rate of confirmed relapses was used. An extension trial after the first 12 months, when all the subjects were treated with GA $40 \mathrm{mg}$ OD, was terminated early as superiority could not be demonstrated [21].

\section{Data required for the Marketing Authorisation of GA copies}

\section{United States}

\section{Glatiramer acetate $20 \mathrm{mg} / \mathrm{ml}$ and $40 \mathrm{mg} / \mathrm{ml}$}

In the United States, since Copaxone ${ }^{\circledR}$ copies are considered to be generics, the FDA required the demonstration of both pharmaceutical equivalence and bioequivalence. Demonstration of pharmaceutical equivalence, though, relies on the fact the two product contain the same active pharmaceutical ingredients (APIs). Currently, there is no single physicochemical or biological assay that can be used to demonstrate API sameness between Copaxone ${ }^{\circledR}$ and a copy. However, FDA's position has been that API sameness can be demonstrated using a battery of orthogonal methods and an approach based on four criteria, developed by the Office of Generic Drugs (ODG): 
1. equivalence of fundamental reaction scheme;

2. equivalence of physicochemical properties including composition;

3. equivalence of structural signatures for polymerization and depolymerization;

4. equivalence of biological assay results.

These criteria may be used to demonstrate API sameness even when the manufacturer of a copy does not entirely know the manufacturing steps used by the manufacturer of the originator [31]. The first three criteria constitute successive refinements of API sameness demonstration. The first criterion aims to ensure that the API of generic GA is produced by an equivalent reaction scheme, as it can be determined using publicly available information, such as the published work by Teitelbaum and coworkers [32] and Teva's patents [33]. The reaction scheme involves two steps: (1) the polymerization of activated amino acids to form an intermediate copolymer, and (2) the partial depolymerization of the intermediate copolymer to yield GA [14]. The FDA requires the use of the same (or equivalent) activated amino acids, initiator and chemical reagents for acid-catalyzed cleavage.

The equivalence of physicochemical properties should be assessed by AA content and optical purity, MW distribution (including molar mass moments and polydispersity) and spectroscopic fingerprints, including, but not limited to, Fourier Transformation Infrared spectroscopy (FT-IR), nuclear magnetic resonance spectra $\left({ }^{1} \mathrm{H}\right.$ and $\left.{ }^{13} \mathrm{C} \mathrm{NMR}\right)$ and circular dichroism (CD). In general, common nonspecific analytical methods, such as size exclusion chromatography (SEC) for MW distribution analysis or AA ratio determination are not considered able to differentiate between structurally related constituents. Moreover, methods requiring previous chemical or enzymatic cleavage of the polypeptides are not optimal, since the nature of the complex active substance is lost during fragmentation and the only reliable way to compare glatiramoids is in its original form [12]. Other methods have been shown to be able to differentiate between Teva's Copaxone ${ }^{\circledR}$ and glatiramoids produced by other manufacturers [12], though not the ones approved in the US or EU as copies of Copaxone®: Glatimer® (produced by NATCO and commercialized in India), 
Escadra ${ }^{\circledR}$ (produced by Raffo and commercialized in Argentina) and Probioglat ${ }^{\circledR}$ (produced by Probiomed and commercialized in Mexico) [34]:

- Capillary Isoelectric Focusing (IEF) gives information on the primary structure of polypeptides by measuring charge distribution. It is relevant in the case of glatiramoids since the polypeptide chains are rich in charged residues (Lys and Glu). This technique has shown high batch-to-batch consistency for 5 batches of Copaxone ${ }^{\circledR}$, while revealing dissimilarities with its copies.

- Dynamic Light Scattering (DLS) is used to assess particle size distribution, by measuring the fluctuations of the scattering intensity of a laser beam hitting the particles in suspension, which are subject to Brownian motion. Data analysis allows for the calculation of the Diffusion coefficient (D). From D, the Radius (R) of the particles can then be obtained from the Stokes-Einstein equation

$$
D=\frac{K_{b} T}{6 \pi \eta R}
$$

where $\mathrm{K}_{\mathrm{b}}$ is Boltzmann constant, $\mathrm{T}$ is absolute temperature, $\eta$ is the dynamic viscosity, and $\mathrm{R}$ is the radius of the particle. This technique has shown high batch-to-batch consistency for 10 batches of Copaxone ${ }^{\circledR}$, while revealing dissimilarities with its copies.

- Atomic Force Microscopy (AFM), which allows analyzing the morphology of aggregates, has shown consistent linear structures in the case of Copaxone ${ }^{\circledR}$ samples and different aggregate appearance in the case of copies.

- Ion Mobility Mass Spectrometry (IMMS), which allows for 2D separation of ionized molecules on the basis of size, shape and mass-charge ratio, can differentiate between closely related molecules, such as isomeric peptides. This technique has shown high batchto-batch consistency for 15 batches of Copaxone ${ }^{\circledR}$, while revealing dissimilarities with its copies. 
Demonstration of equivalence of structural signatures for polymerization and depolymerization is needed since, although the fundamental reaction scheme of the generic is equivalent to the originator's, other relevant information about Teva's manufacturing process, including process conditions, is proprietary and not publicly available.

The fourth criterion is a confirmation of the first three. The EAE assay is considered by the OGD the most useful biological assay for confirmation of API sameness, even though various biochemical assays, such as T-cell activation, antigen presenting cell activation and anti-GA antibodies may be useful complementary tests.

Copaxone $^{\circledR}(20 \mathrm{mg}$ and $40 \mathrm{mg})$ and its copies, Glatiramer acetate Mylan, and Glatopa ${ }^{\circledR}$ are considered therapeutically equivalent (AP code in the Orange Book) [33].

\section{European Union}

\section{Glatiramer acetate $20 \mathrm{mg} / \mathrm{ml}$}

In the EU, the first copy of Copaxone ${ }^{\circledR} 20 \mathrm{mg} / \mathrm{ml}$ was approved in 2016 with a decentralized procedure, under Article 10(3) of Directive 2001/83/EC (hybrid application). As for the dossier requirements, the regulatory agencies required a comparative characterization study with Copaxone $^{\circledR}$. The Applicant (Synthon), in agreement with the EMA, also provided non-clinical and clinical data in support of similarity. As for the non-clinical aspects, Synthon provided data from an EAE mouse model, two 28-days studies and one 90-days comparative toxicity study performed in rats [35]. As for the clinical aspects, following EMA's recommendation, Synthon performed a comparative clinical trial to assess the efficacy, safety, and tolerability of both prolonged treatment with Synthon's copy (GTR) and switching from Copaxone ${ }^{\circledR} 20 \mathrm{mg}$ OD to GTR $20 \mathrm{mg}$ OD [36]. The study, named Glatiramer Acetate Clinical Trial to assess Equivalence with Copaxone ${ }^{\circledR}$ (GATE), was a 9-month randomized clinical trial on 794 patients $\left(\right.$ Copaxone $^{\circledR}, \mathrm{n}=357$; GTR, n=353; placebo, $\mathrm{n}=84$ ) [37], with a 15 months open label follow-up, where 728 subjects from the double blind part were switched to GTR $[38,39]$. In the double blind part, the estimated mean numbers of T1 Gd- 
enhancing lesions at months 7 to 9 (primary outcome) for the Copaxone ${ }^{\circledR}$ and GTR groups were significantly lower than for the placebo group [37].

As for clinical outcomes, the annualized relapse rate (ARR) was (95\% CI in parenthesis) $0.31(0.20 ; 0.48)$ in the GTR group, $0.40(0.26 ; 0.62)$ in the Copaxone group, and $0.38(0.22 ; 0.66)$ in the placebo group. Surprisingly, the ARR observed in the Copaxone ${ }^{\circledR}$ group was not significantly different from that in the placebo group [37], while in a previous study [40] Copaxone ${ }^{\circledR}$ had shown to decrease the ARR significantly. This could be due to the fact that the study was too short in duration and was not powered to assure sensitivity on these endpoints. During the open-label phase, ARR $(95 \%$ CI) was $0.21(0.13 ; 0.34)$ in the GTR/ GTR group, $0.24(0.15 ; 0.39)$ in the Copaxone ${ }^{\circledR} /$ GTR group, and $0.23(0.12 ; 0.42)$ in the placebo/ GTR group. The ARR $(95 \%$ CI) for the total study duration (24 months) was $0.25(0.18 ; 0.37), 0.31(0.22 ; 0.45)$ and $0.30(0.19 ; 0.47)$, respectively [39]. The divergence in MRI and clinical activity contrasts with results from a previous meta-analysis [41]. However, the correlation between MRI and clinical activity has never been accepted by the FDA as a primary endpoint in pivotal MS trials [42].

\section{Glatiramer acetate $\mathbf{4 0} \mathbf{m g} / \mathrm{ml}$}

To support the hybrid application GTR $40 \mathrm{mg} / \mathrm{ml}$ in the EU, Synthon used clinical data from the GATE clinical study (comparing Copaxone ${ }^{\circledR} 20 \mathrm{mg} / \mathrm{ml}$ to GTR $20 \mathrm{mg} / \mathrm{ml}$ ), the GALA clinical study (comparing Copaxone ${ }^{\circledR} 40 \mathrm{mg} / \mathrm{ml}$ to placebo) and four published clinical studies (partly used in the application for Copaxone ${ }^{\circledR} 40 \mathrm{mg} / \mathrm{ml}$ ). Indeed, extrapolation of the results of the GATE study data to the $40 \mathrm{mg} / \mathrm{ml}$ strength TIW could not be based only on reference to Copaxone ${ }^{\circledR}$, since no direct comparison exists between Copaxone ${ }^{\circledR} 20 \mathrm{mg}$ OD and Copaxone ${ }^{\circledR} 40 \mathrm{mg}$ TIW, in terms of efficacy. Therefore, Synthon proposed a bridging scheme in three steps:

- Bridge 1. Demonstration of clinical equivalence between Copaxone® $20 \mathrm{mg} / \mathrm{ml}$ and GTR 20 $\mathrm{mg} / \mathrm{ml}$. It was based on the demonstration of quality similarity (through chemical and biological assays comparing the active substances in the two products), in vitro and in vivo 
similarity (based on data from an EAE mouse model, ex vivo T-cell and PBMC assays and gene expression data in THP-1 cells) and clinical similarity (through the GATE study).

- Bridge 2. Demonstration of clinical equivalence between GTR $20 \mathrm{mg} / \mathrm{ml}$ and GTR $40 \mathrm{mg} / \mathrm{ml}$, which comprised quality, in vitro and in vivo studies to confirm clinical equivalence between the two products. No clinical similarity was required because the two products only differ in concentration.

- Bridge 3. Demonstration of and clinical equivalence between GTR $40 \mathrm{mg} / \mathrm{ml} \mathrm{TIW}$ and Copaxone ${ }^{\circledR} 40 \mathrm{mg} / \mathrm{ml}$ TIW (Bridge 3). It was based on data showing strong similarities in primary structure, physico-chemical properties, higher order structures and biological activity for the active substance of the four products considered (GTR $20 \mathrm{mg} / \mathrm{ml}$, GTR $40 \mathrm{mg} / \mathrm{ml}$, Copaxone ${ }^{\circledR} 20 \mathrm{mg} / \mathrm{ml}$ and Copaxone $\left.{ }^{\circledR} 40 \mathrm{mg} / \mathrm{ml}\right)$.

As a consequence of the above three steps, a clinical bridge (demonstration of clinical similarity) between Synthon's GTR $40 \mathrm{mg} / \mathrm{ml}$ TIW and Copaxone ${ }^{\circledR} 40 \mathrm{mg} / \mathrm{ml}$ TIW was not needed [43].

Data from the GALA study [27] was also provided, along with the data from the GLACIER study, which concluded that tolerability of the switching from Copaxone ${ }^{\circledR} 20 \mathrm{mg} / \mathrm{ml} \mathrm{OD}$ to the 40 $\mathrm{mg} / \mathrm{ml}$ strength TIW is acceptable in RRMS patients [44], the 9006 and the FORTE studies, which compared Copaxone ${ }^{\circledR} 20 \mathrm{mg} / \mathrm{ml}$ OD to Copaxone ${ }^{\circledR} 40 \mathrm{mg} / \mathrm{ml}$ OD $[28,29,45]$. However, the last two studies have been considered of limited value for the assessment of therapeutic equivalence for questionable assay sensitivity, too wide confidence intervals and a dose regime of once daily instead of TIW [43].

\section{Discussion and Conclusion}

Due to their complex structure and to the dependence of their quality profile on the manufacturing process, complex drugs present specific issues related to therapeutic equivalence of copies and originators. In particular, GA is a heterogeneous mixture of not fully characterized 
synthetic polypeptides, whose amino acid sequences are not completely conserved from batch to batch.

From a physico-chemical point of view, different NBCDs products can be characterized by micro- and macro-heterogeneity. Micro-heterogeneity is typical of different batches of each specific commercial product, while different commercial products can be differentiated on the basis of macro-heterogeneity. In the case of GA and other complex active substances, a complete characterization could theoretically demonstrate pharmaceutical equivalence. However, even though methods capable of differentiate GA from different manufacturers exist, complete quality data is not available in literature, and may be technically impossible to provide. Moreover standard requirements have not been developed yet, although glatiramer monographs are being drafted in both the European [46] and US Pharmacopoeias [47].

From the point of view of safety, long-term safety of products with comparable efficacy but produced by different manufacturers should be systematically addressed, due to the chronic administration of glatiramer required by MS patients. Indeed, protiramer - a different glatiramoid obtained by Teva through a slightly modified synthetic process and featuring a higher average molecular size than Copaxone ${ }^{\circledR}$ - could not be granted use in human clinics due to the occurrence of a number of adverse reactions. Testing on Copemyl in the GATE clinical trial attracted some criticism for being affected by a number of questionable steps. The selected primary endpoint was imaging (MRI) findings instead of clinical evidence, as is acceptable in phase II but not in phase III clinical trials. Surprisingly, in this specific trial, MRI data and clinical data (number of relapses) does not seem to correlate, contrary to repeated evidence in this field of medical research, including during the tests on Copaxone ${ }^{\circledR}$. Moreover, the last part of the GATE trial sees a shift from a doubleblind to an open 3-arm structure.

Finally, a similar number of patients developing anti-GA antibodies has been found after administration of both the originator, Copaxone ${ }^{\circledR}$, and its copy, Copemyl. The antibodies produced 
after treatment with Copaxone ${ }^{\circledR}$ have been demonstrated not to inactivate the pharmacological outcome of the drug administration [48]; differently, this evidence is not available about antibodies induced by treatment with Copemyl. In the GATE study, the measurement and classification of the different antibody classes/isotypes induced by Copemyl treatment and of the related anti-GA antibodies are not available.

\section{Conclusion}

For the approval of GA copies, regulatory agencies in the US and the EU are currently oriented toward a generic approach supplemented by additional data. However, this path has been implemented differently in the two jurisdictions (Figure 1). In the US, the additional data required is listed in a product specific guideline. Copies of Copaxone ${ }^{\circledR}$ have been approved by the FDA as generics based on an Abbreviated New Drug Application. In the EU, regulatory agencies followed a hybrid approach requiring an additional comparative study, while interchangeability policies and substitution schemes has been left to national agencies.

Figure 1. Regulatory pathways for Glatiramer Acetate in the US and EU. ANDA = Abbreviated New Drug Application, API = Active Pharmaceutical Ingredient

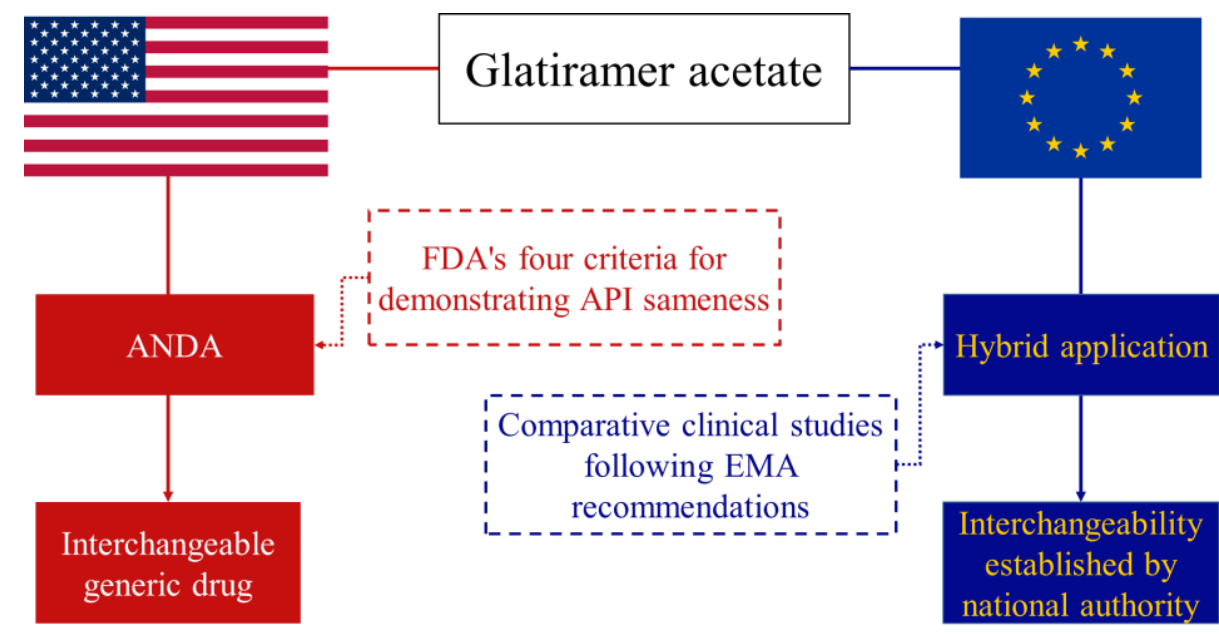

Clearly, an alignment of US and EU policies would be desirable to help companies in the development and marketing of NBCD copies. There are two points where policies in the two jurisdictions seem to converge: neither the FDA nor the European agencies have introduced an ad hoc regulatory class for NBCDs. The path taken by the FDA, i.e. the development of product specific guidelines for different 
NBCDs may pave the way to a similar approach by the EMA. At the same time, monographs for NBCDs are being drafted in the European and US Pharmacopoeias. .

In view of the above and in the light of current knowledge and technological developments it is important, regardless of the regulatory approach, that the prescribing physician is always able to trace the actual complex drug administered to each patient. 
Table 1. Efficacy results for Study 1 [25].

\begin{tabular}{|l|c|c|c|}
\hline \multicolumn{1}{|c|}{ Outcome } & Copaxone ${ }^{\circledR}(\mathbf{n = 2 5})$ & Placebo $(\mathbf{n = 2 5})$ & p-value \\
\hline Relapse-free patients (\%) & $14 / 25(56 \%)$ & $7 / 25(28 \%)$ & 0.085 \\
\hline Mean relapse frequency & $0.6 / 2$ years & $2.4 / 2$ years & 0.005 \\
\hline Median time to first relapse (days) & $>700$ & 150 & 0.03 \\
\hline Progression free patients (\%) & $20 / 25(80 \%)$ & $13 / 25(52 \%)$ & 0.07 \\
\hline $\begin{array}{l}\text { Reduction in relapse rate compared to } \\
\text { pre-study }\end{array}$ & 3.2 & 1.6 & 0.025 \\
\hline
\end{tabular}

Table 2. Efficacy results for Study 2 [25].

\begin{tabular}{|l|c|c|c|}
\hline \multicolumn{1}{|c|}{ Outcome } & Copaxone ${ }^{\circledR}(\mathbf{n = 1 2 5})$ & Placebo $(\mathbf{n = 1 2 6})$ & p-value \\
\hline Relapse free patients (\%) & $42 / 125(34 \%)$ & $34 / 126(27 \%)$ & 0.25 \\
\hline Mean relapse frequency & $1.19 / 2$ years & $1.68 / 2$ years & 0.055 \\
\hline Median time to first relapse (days) & 287 & 198 & 0.23 \\
\hline Progression free patients (\%) & $98 / 125(78 \%)$ & $95 / 126(75 \%)$ & 0.48 \\
\hline $\begin{array}{l}\text { Change in relapse rate compared to pre- } \\
\text { study }\end{array}$ & -0.05 & +0.21 & 0.023 \\
\hline
\end{tabular}

Table 3: MS-GA-301 GALA Study efficacy and MRI Results [21].

\begin{tabular}{|c|c|c|c|}
\hline Outcome & $\begin{array}{c}\text { Copaxone }{ }^{\circledR} 40 \mathrm{mg} / \mathrm{ml} \\
(\mathrm{n}=943)\end{array}$ & $\begin{array}{l}\text { Placebo } \\
(n=461)\end{array}$ & p-value \\
\hline \multicolumn{4}{|c|}{ Number of confirmed relapses during the 12-month placebo-controlled phase } \\
\hline Adjusted Mean Estimates & 0.331 & 0.505 & $<0.0001$ \\
\hline Relative risk reduction & $34 \%$ & & \\
\hline \multicolumn{4}{|c|}{ Cumulative number of new or enlarging T2 lesions (months 6 and 12) } \\
\hline Adjusted Mean Estimates & 3.650 & 5.592 & $<0.0001$ \\
\hline Relative risk reduction & $35 \%$ & & \\
\hline \multicolumn{4}{|c|}{ Cumulative number of enhancing lesions on T1-weighted images (months 6 and 12) } \\
\hline Adjusted Mean Estimates & 0.905 & 1.639 & $<0.0001$ \\
\hline Relative risk reduction & $45 \%$ & & \\
\hline
\end{tabular}




\section{References}

${ }^{1}$ Minghetti P, Rocco P, Cilurzo F, Vecchio LD, Locatelli F. The regulatory framework of biosimilars in the European Union. Drug Discov Today. 2012 Jan;17(1-2):63-70.

${ }^{2}$ Crommelin DJ, de Vlieger JS, Weinstein V, Mühlebach S, Shah VP, Schellekens H. Different pharmaceutical products need similar terminology. AAPS J. 2014;16(1):11-4.

${ }^{3}$ Rocco P, Musazzi UM, Franzè S, Minghetti P. Copies of nonbiological complex drugs: generic, hybrid or biosimilar? Drug Discov Today. 2018; pii:S1359-6446(18)30082-5.

${ }^{4}$ Weinstock-Guttman B, Nair KV, Ganguly TC, Kantor D.Two decades of glatiramer acetate: From initial discovery to the current development of generics. Journal of the Neurological Sciences; 2017, 376:255-259.

${ }^{5}$ Kremer D, Küry P, Dutta R. Promoting remyelination in multiple sclerosis: Current drugs and future prospects. Mult Scler. 2015 Apr;21(5):541-9.

${ }^{6}$ Mayo L, Quintana FJ, Weiner HL. The innate immune system in demyelinating disease. Immunol Rev. 2012 Jul;248(1):170-87.

${ }^{7}$ Kutzelnigg A, Lucchinetti CF, Stadelmann C, Brück W, Rauschka H, Bergmann M, Schmidbauer M, Parisi JE, Lassmann H. Cortical demyelination and diffuse white matter injury in multiple sclerosis. Brain. 2005 Nov;128(Pt 11):2705-12.

${ }^{8}$ Hurwitz BJ. The diagnosis of multiple sclerosis and the clinical subtypes. Ann Indian Acad Neurol. 2009;12(4):226-30.

${ }^{9}$ Goldenberg MM. Multiple sclerosis review. P T. 2012 Mar;37(3):175-84.

${ }^{10}$ Medicines and Healthcare products Regulatory Agency (MHRA). Public Assessment Report. Mutual Recognition Procedure. Copaxone $20 \mathrm{mg} / \mathrm{ml}$ solution for injection prefilled syringe (UK/H/0453/002/E01). Available at http://www.mhra.gov.uk/home/groups/par/documents/websiteresources/con025676.pdf. Last Accessed on 09/12/2018.

${ }^{11}$ Varkony H, Weinstein V, Klinger E, Sterling J, Cooperman H, Komlosh T, Ladkani D, Schwartz R. The glatiramoid class of immunomodulator drugs. Expert Opin Pharmacother. 2009;10(4):657-68.

${ }^{12}$ Weinstein V, Schwartz R, Grossman I, Zeskind B, Michael Nicholas JM. Glatiramoids. In NonBiological Complex Drugs. The Science and the Regulatory Landscape, Crommelin DJA and de Vlieger JSB (Eds.), Springer, Cham, 2015.

${ }^{13}$ Carter NJ, Keating GM. Glatiramer acetate: a review of its use in relapsing-remitting multiple sclerosis and in delaying the onset of clinically definite multiple sclerosis. Drugs. 2010;70(12):1545-77.

${ }^{14}$ U.S. Food and Drug Administration. Center for Drug Evaluation and Research (CDER). Approval Package for: Application Number: ANDA 09218 (04/16/2015). Last accessed on 07/28/2018.

${ }^{15}$ Schellekens H, Klinger E, Mühlebach S, Brin JF, Storm G, Crommelin DJ. The therapeutic equivalence of complex drugs. Regul Toxicol Pharmacol. 2011;59(1):176-83.

${ }^{16}$ Borchard G, Crommelin DJA. Equivalence of glatiramer acetate products: challenges in assessing pharmaceutical equivalence and critical clinical performance attributes. Expert Opin Drug Deliv. 2017;22:1-13.

${ }^{17}$ Ramot Y, Rosenstock M, Klinger E, Bursztyn D, Nyska A, Shinar DM. Comparative long-term preclinical safety evaluation of two glatiramoid compounds (glatiramer Acetate, Copaxone(R), and TV-5010, protiramer) in rats and monkeys. Toxicol Pathol. 2012;40(1):40-54.

${ }^{18}$ U.S. Government Accountability Office. Report to Congressional Requesters. Generic Drugs. FDA Should Make Public Its Plans to Issue and Revise Guidance on Nonbiological Complex 
Drugs. GAO-18-80 (2017). Available at https://www.gao.gov/products/GAO-18-80. Last accessed on 8 May 2018.

${ }^{19}$ Regulation (EC) No 726/2004 of the European Parliament and of the Council of 31 March 2004 laying down Community procedures for the authorisation and supervision of medicinal products for human and veterinary use and establishing a European Medicines Agency. Available at http://eur-lex.europa.eu/legal-content/EN/TXT/?uri=celex\%3A32004R0726.

${ }^{20}$ Heads of Medicines Agencies (HMA). The MRI Product Index. Available at https://mri.ctsmrp.eu/Human/. Last accessed on 10 May 2018.

${ }^{21}$ Food and Drug Administration. Center for Drug Evaluation and Research (CDER). Approval Package for: Application Number: NDA 20622/S89 (01/28/2014). Last accessed on 07/28/2018.

${ }^{22}$ Food and Drug Administration. Copaxone - Full prescribing information (01/23/2018). Available at https://www.accessdata.fda.gov/drugsatfda_docs/label/2018/020622s102lbl.pdf. Last accessed on $07 / 31 / 2018$.

${ }^{23}$ Intellectual Property Office (UK). Supplementary Protection Certificate. Copaxone (SPC/GB02/029, 5 August 2002). Available at: https://www.ipo.gov.uk/p-find-spc-byspcresults.htm?number=SPC/GB02/029. KLast accessed on 07/30/2018.

${ }^{24}$ Teva UK Ltd. Copaxone $20 \mathrm{mg} / \mathrm{ml}$ - Summary of product characteristics (04/26/2013). Available at: http://www.tevauk.com/mediafile/id/15860.pdf. Last accessed on 07/31/2018.

${ }^{25}$ U.S. Food and Drug Administration. Center for Drug Evaluation and Research (CDER). Approval Package for: Application Number: NDA 20-622/S-015 (07/12/2001). Last accessed on 07/28/2018.

${ }^{26}$ Medicines and Healthcare products Regulatory Agency (MHRA). Public Assessment Report. Copaxone $20 \mathrm{mg} / \mathrm{ml}$ solution for injection prefille syringe (UK licence no: PL 10921/0023). Summary of Product Characteristics. Available at http://www.mhra.gov.uk/home/groups/spcpil/documents/spcpil/con1523593201167.pdf. Last Accessed on 07/29/2018.

${ }^{27}$ Khan O, Rieckmann P, Boyko A, Selmaj K, Zivadinov R; GALA Study Group. Three times weekly glatiramer acetate in relapsing-remitting multiple sclerosis. Ann Neurol. 2013 Jun;73(6):705-13.

${ }^{28}$ Medicines and Healthcare products Regulatory Agency (MHRA). Public Assessment Report. Copaxone $40 \mathrm{mg} / \mathrm{ml}$ Solution for Injection Pre-Filled Syringe (UK/H/0453/004/DC). Available at http://www.mhra.gov.uk/home/groups/par/documents/websiteresources/con521776.pdf. Last Accessed on 09/12/2018.

${ }^{29}$ Cohen JA, Rovaris M, Goodman AD, Filippi M, and the MRI-AC Study Group, the 9006 Study Group. Results of a randomized, double-blind, parallel-group study assessing safety and efficacy of $40 \mathrm{mg}$ vs. $20 \mathrm{mg}$ of glatiramer acetate on MRI-measured disease activity in RRMS. Neurology 2006; 67(1):185.

${ }^{30}$ Comi G, Cohen JA, Arnold DL, Wynn D, Filippi M; FORTE Study Group. Phase III dosecomparison study of glatiramer acetate for multiple sclerosis. Ann Neurol. 2011;69(1):75-82.

${ }^{31}$ U.S. Food and Drug Administration. Draft Guidance on Glatiramer Acetate Injection, 2016. Available at https://www.fda.gov/Drugs/GuidanceComplianceRegulatoryInformation/Guidances/ucm075207. htm. Last accessed on 02/02/2018.

32 Teitelbaum D, Meshorer A, Hirshfeld T, Arnon R, Sela M. Suppression of experimental allergic encephalomyelitis by a synthetic polypeptide. Eur J Immunol. 1971 Aug;1(4):242-8.

${ }^{33}$ U.S. Food and Drug Administration. Approved Drug Products With Therapeutic Equivalence Evaluations (Orange Book), 38th Edition. Available at https://www.accessdata.fda.gov/scripts/cder/ob/. Last accessed on 12 April 2018.

${ }^{34}$ Annovazzi P, Bertolotto A, Brescia Morra V, Gasperini C, Montanari E, Navarra P, Patti F, Sormani MP, Ghezzi A. A Comprehensive Review on Copemyl®. Neurol Ther. 2017 Dec;6(2):161-173. 
${ }^{35}$ College ter Beoordeling van Geneesmiddelen (Medicines Evaluation Board, CBG/MEB). Public Assessment Report. Scientific discussion. Glatiramer acetate $20 \mathrm{mg} / \mathrm{ml}$ solution for injection, pre-filled syringe (2016). Available at https://mri.cts-mrp.eu/Human/Downloads/ NL_H_3213_001_PAR.pdf. Last accessed on 07/28/2018.

${ }^{36}$ Bourdette D, Hartung D. Equivalence of Glatiramer Acetate Generics With Branded Glatiramer Acetate in Efficacy and Cost for the Treatment of Multiple Sclerosis. JAMA Neurol. 2015 Dec;72(12):1411-3.

${ }^{37}$ Cohen J, Belova A, Selmaj K, Wolf C, Sormani MP, Oberyé J, van den Tweel E, Mulder R, Koper N, Voortman G, Barkhof F. Glatiramer Acetate Clinical Trial to Assess Equivalence With Copaxone (GATE) Study Group. Equivalence of Generic Glatiramer Acetate in Multiple Sclerosis: A Randomized Clinical Trial. JAMA Neurol. 2015;72(12):1433-41.

${ }^{38}$ Selmaj K, Barkhof F, Belova AN, Wolf C, van den Tweel ERW, Oberyé JJL, Mulder R, Egging DF, Koper NP, Cohen JA, and on behalf of the GATE study group. Switching from branded to generic glatiramer acetate: 15-month GATE trial extension results. Mult Scler. 2017; 23(14): 1909-1917.

${ }^{39}$ College ter Beoordeling van Geneesmiddelen (Medicines Evaluation Board, CBG/MEB). Public Assessment Report. Scientific discussion. Schlerton $20 \mathrm{mg} / \mathrm{ml}$ solution for injection, pre-filled syringe (2016). Available at https://mri.cts-mrp.eu/Human/Downloads/ NL_H_3212_001_PAR.pdf. Last accessed on 08/09/2018.

${ }^{40}$ Comi G, Filippi M, Wolinsky JS. European/Canadian multicenter, double-blind, randomized, placebo-controlled study of the effects of glatiramer acetate on magnetic resonance imaging-measured disease activity and burden in patients with relapsing multiple sclerosis.

European/Canadian Glatiramer Acetate Study Group. Ann Neurol. 2001;49(3):290-7.

${ }^{41}$ Sormani MP, Bruzzi P. MRI lesions as a surrogate for relapses in multiple sclerosis: a metaanalysis of randomised trials. Lancet Neurol. 2013;12(7):669-76.

${ }^{42}$ Sørensen PS. Multiple sclerosis. Generic glatiramer acetate--a step toward cheaper MS drugs? Nat Rev Neurol. 2016;12(1):5-6.

${ }^{43}$ College ter Beoordeling van Geneesmiddelen (Medicines Evaluation Board, CBG/MEB). Public Assessment Report. Scientific discussion. Sclerthon $40 \mathrm{mg} / \mathrm{ml}$, solution for injection, pre-filled syringe (2018). Available at https://mri.ctsmrp.eu/Human/Downloads/NL_H_3779_001_PAR.pdf. Last accessed on 07/29/2018.

${ }^{44}$ Wolinsky JS, Borresen TE, Dietrich DW, Wynn D, Sidi Y, Steinerman JR, Knappertz V, Kolodny S; GLACIER Study Group. GLACIER: An open-label, randomized, multicenter study to assess the safety and tolerability of glatiramer acetate $40 \mathrm{mg}$ three-times weekly versus $20 \mathrm{mg}$ daily in patients with relapsing-remitting multiple sclerosis. Mult Scler Relat Disord. 2015;4(4):370-6.

${ }^{45}$ Cohen JA, Rovaris M, Goodman AD, Ladkani D, Wynn D, Filippi M; 9006 Study Group. Randomized, double-blind, dose-comparison study of glatiramer acetate in relapsing-remitting MS. Neurology. 2007;68(12):939-44.

${ }^{46}$ European Directorate for the Quality of Medicines. Knowledge Database. Available at: https://extranet.edqm.eu/publications/recherches_sw.shtml. Search performed on 2 March 2019; Search string: "glatiramer". Last accessed on March 2, 2019.

${ }^{47}$ USP. Glatiramer Expert Panel of the Biologics Monographs 1 - Peptides and Insulins Expert Committee (October 16 - 17, 2017). Agenda (Draft). Available at: https://www.usp.org/sites/default/files/usp/document/glatiramer-expert-panel-agenda.pdf. Last accessed on March 2, 2019.

${ }^{48}$ Brenner T, Arnon R, Sela M, Abramsky O, Meiner Z, Riven-Kreitman R, Tarcik N, Teitelbaum D. Humoral and cellular immune responses to Copolymer 1 in multiple sclerosis patients treated with Copaxone. J Neuroimmunol. 2001;115(1-2):152-60. 